\title{
Oct2 enhances antibody-secreting cell differentiation through regulation of IL-5 receptor $\alpha$ chain expression on activated $B$ cells
}

\author{
Dianne Emslie, ${ }^{1}$ Kathy D’Costa, ${ }^{1}$ Jhagvaral Hasbold, ${ }^{1}$ Donald Metcalf, ${ }^{2}$ \\ Kiyoshi Takatsu, ${ }^{3}$ Philip O. Hodgkin, ${ }^{1}$ and Lynn M. Corcoran ${ }^{1}$ \\ ${ }^{1}$ Immunology Division and ${ }^{2}$ Division of Cancer and Haematology, The Walter and Eliza Hall Institute, Parkville, \\ Victoria 3050, Australia \\ ${ }^{3}$ Division of Immunology, Department of Microbiology and Immunology, The Institute of Medical Science, University of Tokyo, \\ Tokyo 108-8639, Japan
}

Mice lacking a functional gene for the Oct2 transcriptional activator display several developmental and functional deficiencies in the B lymphocyte lineage. These include defective $B$ cell receptor (BCR) and Toll-like receptor 4 signaling, an absence of B-1 and marginal zone populations, and globally reduced levels of serum immunoglobulin $(\mathrm{lg})$ in naive and immunized animals. Oct2 was originally identified through its ability to bind to regulatory regions in the lg loci, but genetic evidence has not supported an essential role for Oct2 in the expression of Ig genes. We describe a new Oct2-mediated role in B cells. Oct2 augments the ability of activated B cells to differentiate to antibody-secreting plasma cells (ASCs) under $T$ cell-dependent conditions through direct regulation of the gene encoding the $\alpha$ chain of the interleukin (IL) 5 receptor. Ectopic expression of IL-5R $\alpha$ in oct2-deficient B cells largely restores their ability to differentiate to functional ASCs in vitro but does not correct other phenotypic defects in the mutants, such as the maturation and specialization of peripheral B cells, which must therefore rely on distinct Oct2 target genes. IL-5 augments ASC differentiation in vitro, and we show that IL-5 directly activates the plasma cell differentiation program by enhancing blimp1 expression.

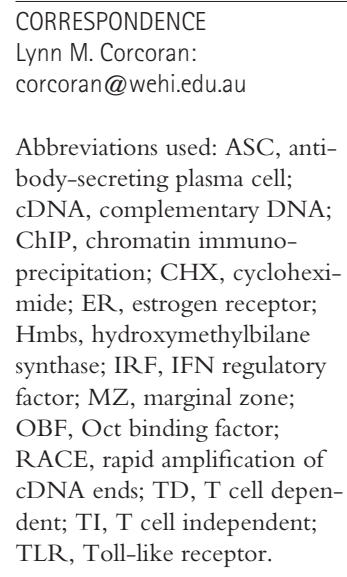

Abbreviations used: ASC, antibody-secreting plasma cell; cDNA, complementary DNA; ChIP, chromatin immunoprecipitation; CHX, cycloheximide; ER, estrogen receptor; Hmbs, hydroxymethylbilane synthase; IRF, IFN regulatory factor; MZ, marginal zone; OBF, Oct binding factor; RACE, rapid amplification of cDNA ends; TD, T cell dependent; TI, T cell independent; TLR, Toll-like receptor.

B cells differentiate to antibody-secreting plasma cells (ASCs) in vivo in response to T cell-independent (TI) antigens, generating extrafollicular ASCs that are short lived and secrete antibody of low affinity. Responses to $\mathrm{T}$ cell-dependent (TD) antigens proceed with different kinetics and in a specialized microenvironment, the germinal center, where $T$ cells collaborate with their cognate $\mathrm{B}$ cells by providing signals that induce rapid division, isotype switching, and somatic hypermutation in the B cells. The ASCs that result from these interactions tend to be long lived and secrete antibodies of high affinity. The T cells signal to the B cell via surface CD40 ligand (CD40L) and cytokines such as IL-4 and IL-5. In the mouse, IL-4 is both a survival factor for B cells and an inducer of isotype switching, primarily to IgG1 and IgE. In contrast, IL-5 acts to increase the likelihood of differentiation of

D. Emslie and K. D'Costa contributed equally to this work. conventional B cells to ASCs $(1,2)$ and supports B-1 cell proliferation, survival, and Ig production (3-6).

The intrinsic genetic program that drives the differentiation of ASCs is becoming clear (7). As a prerequisite, the $\mathrm{B}$ cell and germinal center programs, which are actively maintained in large part by Pax 5 and Bcl6, respectively, must be extinguished. These transcription factors inhibit differentiation by repressing genes that are required for ASC generation or function (8-10). Critical among them is Blimp1, a transcriptional repressor that is essential for the terminal differentiation of ASCs (11-13). Once induced, Blimp1 neutralizes Pax5- and Bc16-mediated repression, thus enabling the expression of the plasma cell-specific gene program, in collaboration with other essential regulators such as IFN regulatory factor (IRF) 4 and Xbp1 (14-16). Recent work has revealed that the initiation of plasma cell differentiation is Blimp1 independent 
and is accompanied by a decrease in Pax5 activity through a posttranslational mechanism that has not yet been explained (17).

However, the extrinsic signals that initiate ASC differentiation are less clear. A strong signal through the BCR is thought to signal Bcl6 degradation and, thus, derepression of blimp1 (18). Bacterial products such as LPS can drive TI ASC differentiation, whereas CD40L and T cell-derived cytokines signal TD ASC differentiation, particularly IL-4, IL-5, and IL-21 in the mouse and IL-6 and IL-10 in humans. Interestingly, recent studies suggest that TD ASC differentiation may require additional regulatory factors compared with TI ASC. For example, the coactivator Oct binding factor $(\mathrm{OBF}) 1$, which regulates several aspects of mature B cell behavior, is selectively required for ASC differentiation in vitro in response to $\mathrm{T}$ cell stimuli and in vivo in response to vaccination with a protein antigen (19). In another study, the Stat 3 protein, which is activated by many cytokines (including IL-6 and IL-10), was shown to be required for the generation of IgG-secreting ASCs (20). These recent findings suggest that the nature of extrinsic regulators of
ASC differentiation, as well as the signaling pathways that they engage, are important but poorly understood determinants of the humoral response.

Oct2, one of the first transcriptional activators recognized in B lymphocytes, was isolated as a nuclear factor that recognizes a conserved motif in the promoters and enhancers of the Ig gene loci. Although early circumstantial findings suggested a role for Oct 2 in the B cell-specific expression of Ig genes, an essential role has not been substantiated by genetic studies $(21,22)$. Instead, postnatal survival and the differentiation and specialization of peripheral B cells depend on this factor $(23,24)$. Nevertheless, serum antibody in naive oct2-null mice and their humoral immune responses are much diminished compared with normal mice. The current study was designed to uncover factors contributing to this immunodeficiency.

As oct $2^{-1-}$ mice display several abnormalities within the B cell compartment, we chose to examine their capacity to differentiate to ASCs under well-defined in vitro conditions, where even small deviations from normal could be quantitatively distinguished (1). We found that oct2-null B cells

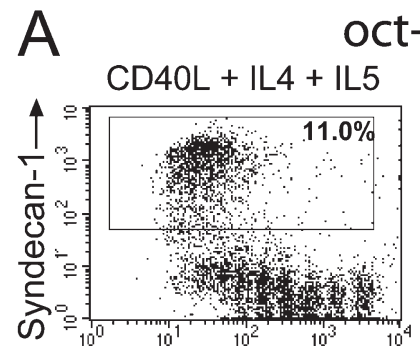

oct $-2+/+$
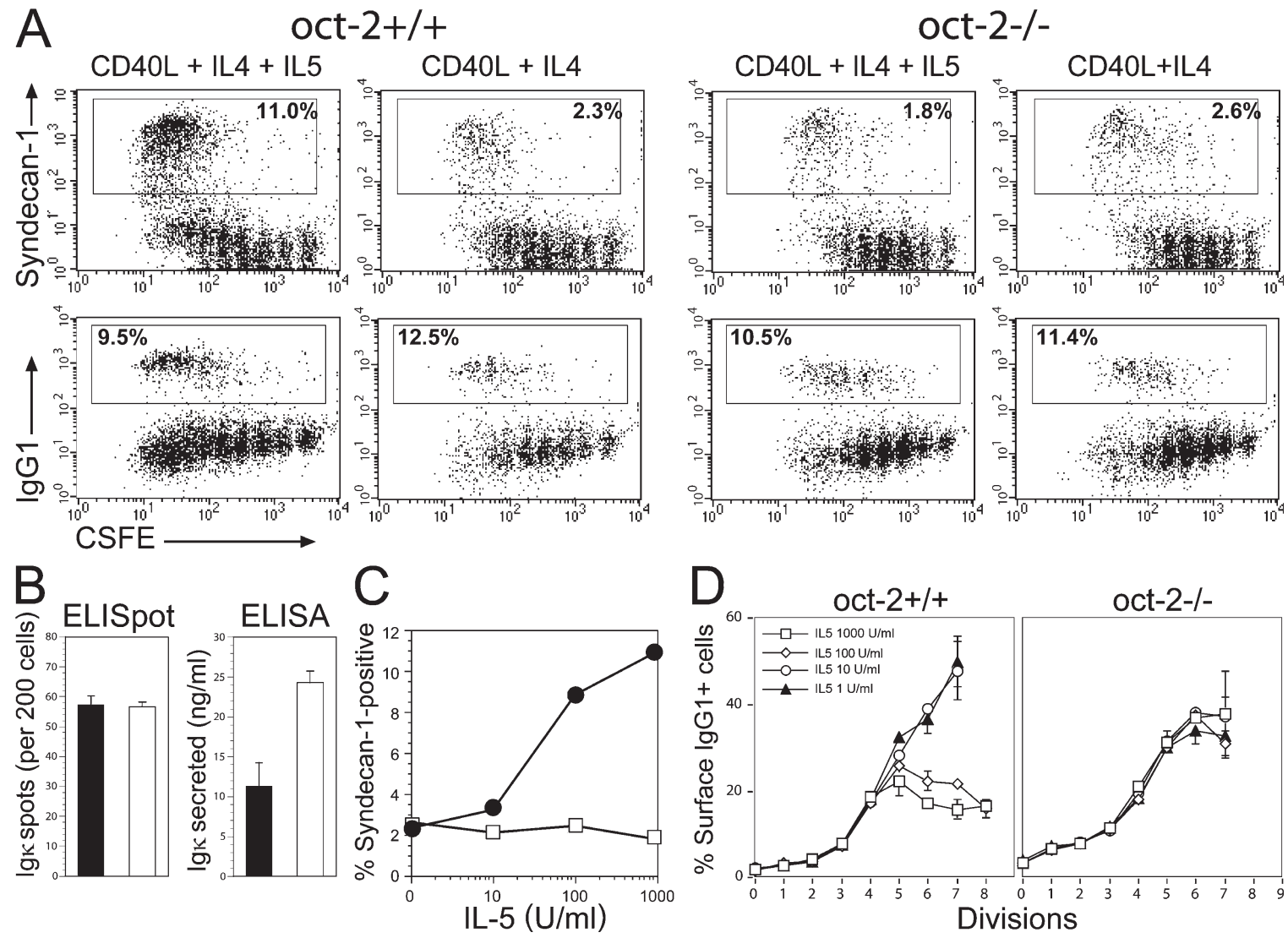

Figure 1. IL-5-enhanced ASC differentiation requires 0ct2. (A) In vitro cultures of CFSE-labeled resting B cells (oct2 $2^{+1+}$ and oct2 ${ }^{-1-}$ ) were stimulated as indicated for $4 \mathrm{~d}$. ASCs were detected using anti-Syndecan 1 staining, and isotype switching to $\lg \mathrm{G} 1$ was also monitored. The percentage of ASCs or switched cells is indicated for each culture. (B, left) ELISPOT assay for lgк secretion was performed on Syndecan $1^{+}$cells sorted on day 4 from CD40L/IL-4 cultures. 200 cells were plated (shaded bars, oct $2^{+/+}$; open bars, oct $2^{-l-}$ ). (right) Comparison, by ELISA, of the amount of lg secreted during $5 \mathrm{~h}$ of culture by 6,000 syndcan $1^{+}$oct $2^{+/+}$and oct ${ }^{-1-}$ ASCs. Values are means \pm SD for triplicate cultures. (C) Percentage of Syndecan $1^{+}$cells on day 4 in CD40L/IL-4 cultures as a function of increasing IL-5 concentration (closed symbols, oct $2^{+1+}$; open symbols, oct $2^{-I^{-}}$). (D) Percentage of isotype-switched (lgG $1^{+}$) cells on day 4 in CD $40 \mathrm{~L} / \mathrm{IL}-4$ cultures as a function of increasing IL-5 concentration and cell division. Values are means \pm SD. 
differentiate normally to fully functional ASCs under conditions that mimic TD conditions (CD40L plus IL-4). Only when the differentiation enhancing cytokine IL-5 was included did the mutant cells behave aberrantly. These studies led to the identification of the inducible chain of the IL-5 receptor, IL-5R $\alpha / C D 125$, as a B cell-specific Oct2 target gene, and to a model whereby IL-5 signaling directly accelerates the ASC differentiation program through increased expression of blimp1. Because Oct2 is required for several important responses in B cells, including BCR and Toll-like receptor (TLR) 4 signaling, several aspects of $\mathrm{B}$ cell differentiation are disturbed in vivo in its absence. Its participation in TD ASC generation is unlikely to have been revealed without the use of the quantitative in vitro analyses used in this study.

\section{RESULTS}

oct2-deficient B cells differentiate normally to phenotypic ASCs in vitro but are insensitive to the enhancing effect of IL-5

Mice lacking the Oct2 transcription factor die perinatally, but reconstitution of immunodeficient $\mathrm{Rag}-1^{-/-}$mice with oct $2^{-/-}$ fetal liver has allowed the behavior of oct2-null lymphoid cells to be assessed. These studies highlighted the contribution that Oct 2 makes to the differentiation of specialized mature B cell subsets (unpublished data) (24). Surprisingly, no evidence from studies on oct 2 mutant mice supports the proposal that Oct2 regulates the transcription of Ig genes, either alone or in conjunction with its sometime partner, the coactivator OBF1/ OCA-B/Bob.1 (25). Nevertheless, the serum of mice reconstituted with oct $2^{-/-}$lymphocytes contains significantly lower levels of Ig of all isotypes than control reconstituted mice, whether naive or immunized (23-25).

We therefore assessed the ability of oct2-null B cells to differentiate to ASCs in vitro in response to CD40L and cytokines. These conditions were chosen for two reasons. First, we have made detailed, quantitative studies of the behavior of normal B cells under these conditions, measuring rates of cell division, isotype switching, and ASC differentiation (1), and we can therefore recognize deviations from normal responses. Second, oct $2^{-1-}$ B cells respond poorly to other polyclonal mitogens, such as LPS and BCR cross-linking antibodies (23, 24, 26), so these activators could not be used.
A
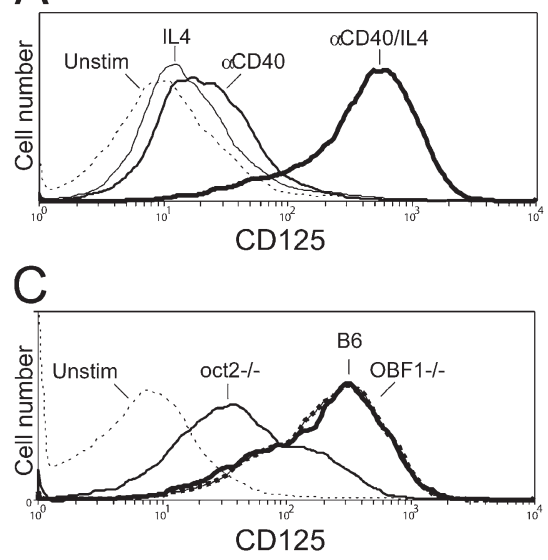

B
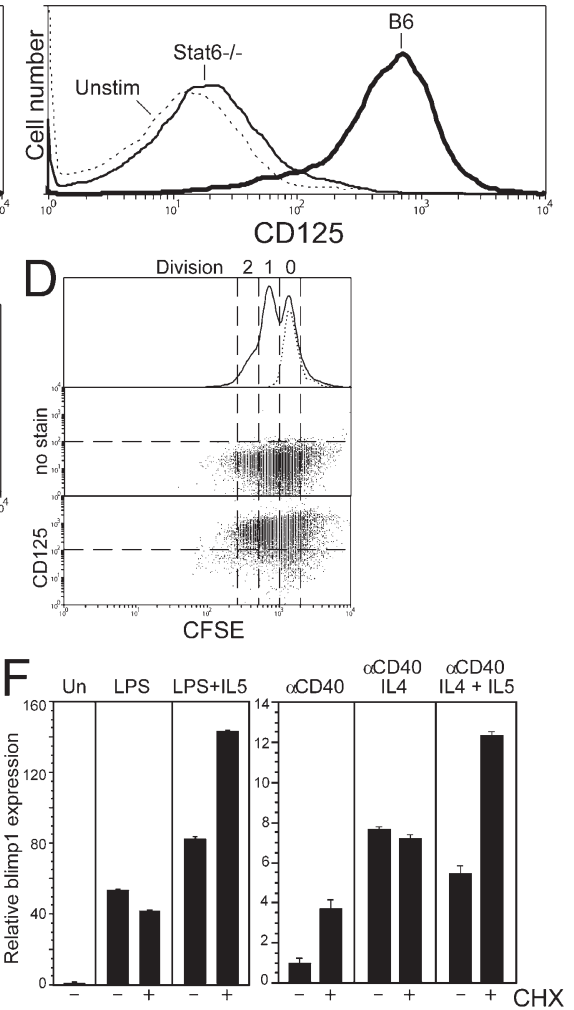

Figure 2. T cell signals up-regulate IL-5R $\alpha$ and blimp1 expression and ASC differentiation. (A) IL-5R $\alpha$ (CD125) up-regulation requires simultaneous CD40 and IL-4 signals. (B) The IL-4 signal is transduced by Stat6. (C) Complete induction of CD125 depends on Oct2 but not OBF1. (D) Induction of CD125 from resting levels requires activation but is not dependent on cell division. CD125 is induced even in undivided cells in anti-CD40+IL-4 cultures of CFSE-labeled resting B cells (dotted line, cells treated with IL-4 only). (E) ASC (Syndecan 1+, blimp/GFP+) numbers are increased in response to IL-5 in in vitro cultures (CD40L/IL-4 plus IL-5, analyzed on day 4). (F) IL-5 treatment enhances blimp1 transcription directly. Real-time PCR measuring blimp1 expression in B cells cultured in LPS (TI conditions) or anti-CD40+IL-4 (TD conditions) were as described in Materials and methods. CHX was added as indicated, and IL-5 was added to some cultures $1 \mathrm{~h}$ later. After a further $5 \mathrm{~h}$, cells were harvested for RNA. Values are normalized to Hmbs, are means of triplicates \pm SD, and are relative to unstimulated cells (for LPS) or $\alpha C D 40$-stimulated cells. 
We found that oct2-null B cells behave indistinguishably from WT B cells in CD40L+IL-4 cultures, undergoing isotype switching to IgG1 and differentiating to Syndecan $1^{+}$ ASCs in a cell division-linked manner (Fig. 1 A). Sorted Syndecan $1^{+}$cells were ASCs, as determined by ELISPOT, and Oct2-deficient ASCs secreted at least as much Ig as did controls (Fig. 1 B).

We previously demonstrated that when IL-5 was added to CD40L+IL-4 cultures, ASC differentiation was enhanced. The ASCs generated in such cultures were rapidly dividing plasmablasts that were no longer able to switch isotypes (1). This IL-5dependent enhancement can be seen in the control cultures of Fig. $1 \mathrm{~A}$ but not in oct $2^{-/-} \mathrm{B}$ cell cultures (Fig. $1 \mathrm{C}$ ). The sensitivity of B cells to IL-5 is also reflected in the percentages of IgG1 ${ }^{+}$cells in cultures with increasing IL-5 concentrations; at high concentrations, switched cells are less frequent in control cultures because a higher proportion of cells have become ASCs, which do not switch (1). In oct $2^{-1-}$ cultures, IL-5 had no effect on the proportion of switched cells, an indirect consequence of the lower frequency of ASC differentiation (Fig. 1 D). These data reveal both a new role for Oct 2 in the cytokine-driven augmentation of ASC production and the absence of an essential role for Oct 2 in the regulation of Ig production by preformed ASCs.

\section{Regulation of IL-5R $\alpha$ expression by T cell signals}

Most resting B cells express the $\beta$ chain but not the $\alpha$ chain of the IL-5 receptor and therefore do not respond to the cytokine. Upon activation, IL-5R $\alpha$ is induced, and the cells become responsive (Fig. 2 A) $(27,28)$. We therefore examined more closely the regulation of IL-5R $\alpha$ expression on WT and mutant B cells. Resting B cells were activated for $2 \mathrm{~d}$ with anti-CD40 antibodies. This treatment did not significantly elevate IL-5R $\alpha$ expression from resting cell levels (Fig. 2 A), indicating that activation alone is not sufficient for IL-5R $\alpha$ induction. Weber et al. (29) reported that IL-4 addition enhanced IL-5R $\alpha$ expression on LPS-treated B cells. We therefore looked for IL-5R $\alpha$ induction in response to IL-4. This cytokine alone did not induce IL-5R $\alpha$, but the combination of $\alpha \mathrm{CD} 40$ and IL- 4 was a strong inducer (Fig. $2 \mathrm{~A}$ ), and this induction required Stat6, the primary signal transducer of the IL-4R (Fig. 2 B). Oct2-deficient B cells failed to completely up-regulate IL-5R $\alpha$ under these conditions, although expression of the receptor rose from resting cell levels (Fig. 2 C). Thus, Oct2 contributes to, but does not entirely control, IL-5R $\alpha$ levels. Despite its role as an integrator of CD40 and IL-4 signals in the context of germinal center development, the coactivator OBF1 had no influence on IL-5R $\alpha$ expression under these conditions (Fig. 2 C).
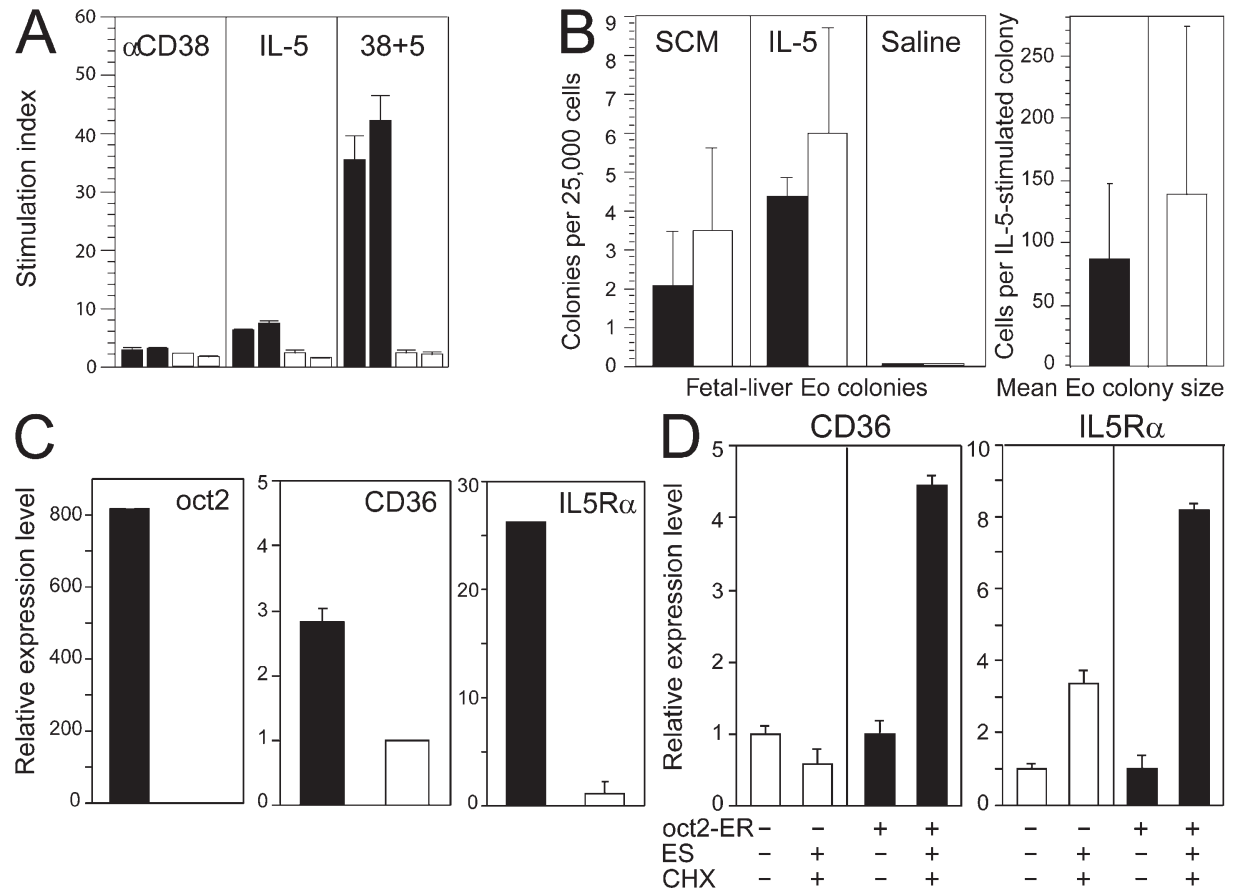

Figure 3. B cell-specific, direct regulation of IL-5R $\alpha$ expression by 0ct2. (A) Anti-CD38 and IL-5 synergize to drive B cell proliferation (reference 66 ). Control B cells proliferated vigorously in response to $\alpha \mathrm{CD} 38$ and IL-5 (shaded bars), but oct2 ${ }^{-1-}$ B cells (open bars) did not. Stimulation index is the ratio of cpm (measuring [ $\left.{ }^{3} \mathrm{H}\right]$-thymidine incorporation) in stimulated cells relative to unstimulated cells. (B) Eosinophil colonies generated from embryonic day 18 fetal liver in response to spleen-conditioned medium (SCM) or IL-5 were enumerated (left), and mean colony size was determined (right; shaded bars, Oct2 $2^{++}$; open bars, oct2 ${ }^{-l-}$ ). (C) Real-time PCR measurement of oct2, CD36, and IL-5R $\alpha$ expression in primary B cells, normalized to Hmbs, and relative to oct2 $^{-1-}$ B cells. (D) Real-time PCR measurement of endogenous CD36 and IL-5R $\alpha$ expression in OM1A (oct2 ${ }^{-1-}$ ) B lymphoma cells and the same cells transduced with a retrovirus expressing an estradiol-inducible version of Oct2. Induction with estradiol (ES) in the presence or absence of CHX is described in Materials and methods. Values are means \pm SD for triplicate samples. 
The observation that ASC differentiation is cell division dependent (1) prompted us to ask whether expression of the IL-5R $\alpha$ chain was also division linked. We purified resting $\mathrm{B}$ cells, labeled them with the cell division tracking dye CFSE, and stained for CD125 expression after $48 \mathrm{~h}$ in culture with $\alpha \mathrm{CD} 40+\mathrm{IL}-4$. The results indicated that IL-5R $\alpha$ is expressed even in undivided B cells (Fig. 2 D). Thus, although IL-5 acts to enhance ASC generation, it is unlikely to contribute significantly to the cell division dependence of this differentiation step.
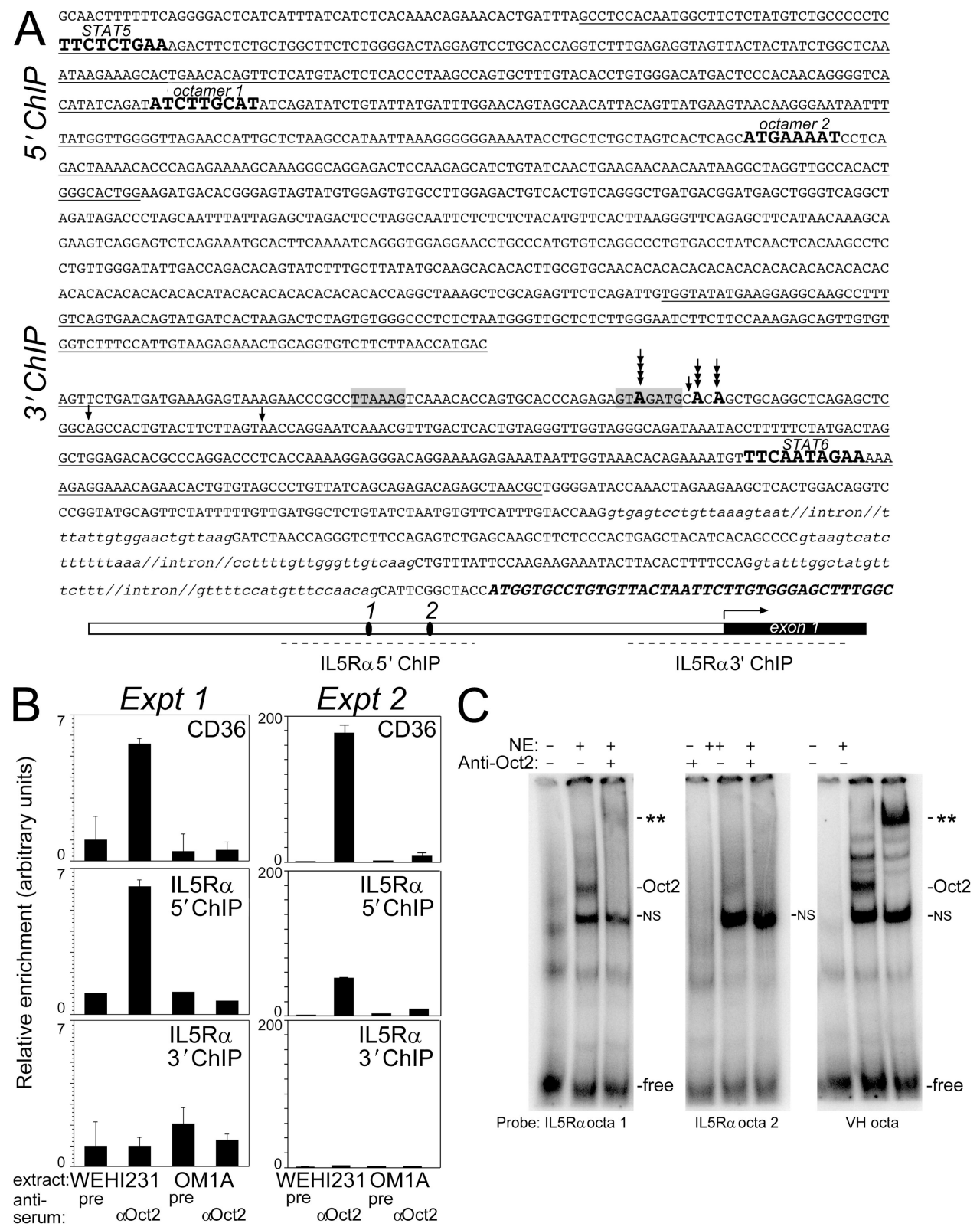

Figure 4. Oct2 binds directly to the IL-5R $\alpha$ gene. (A) Sequence of the 5 ' end of the mouse IL-5R $\alpha$ gene, indicating putative binding sites for $0 c t 2$, Stat5, and Stat6. IL-4 signals through Stat6, and IL-5 signals through Stat3 and 5 to up-regulate IL-5R $\alpha$ expression (reference 33). Vertical arrows mark the $5^{\prime}$ ends of $5^{\prime}$ RACE products (with bolded A residues at the preferred starts). Shaded boxes indicate putative TATA-binding factor and initiator recognition sites. The underlined sequences indicate the ChIP probe fragments. Intronic sequences are in lower case; the coding sequence is bolded. The promoter is represented by a diagram (bottom). (B) Quantitation of ChIP (two independent experiments) of endogenous 0ct2 bound to the CD36 or IL-5R $\alpha$ promoters in control WEHI231 or oct2-deficient OM1A lymphoma cells was performed using standard curves, and the WEHI231/control antibody sample was used as a reference. Values are means \pm SD for triplicates. (C) EMSA showing a complex formed between a nuclear protein in LPS-activated B cells and double-stranded oligonucleotide probes matching the octamer 1 site of A. The presence of Oct2 in the complex is indicated by the supershift $\left.{ }^{* *}\right)$ caused by the addition of a monoclonal anti-Oct2 antibody. The octamer 2 site does not appear to bind significant amounts of Oct2. An oligo spanning the $V_{H}$ 17.2.25 promoter is included as a positive control for Oct2 binding ( $V_{H}$ octa; free, unbound probe). NS, nonspecific band. 

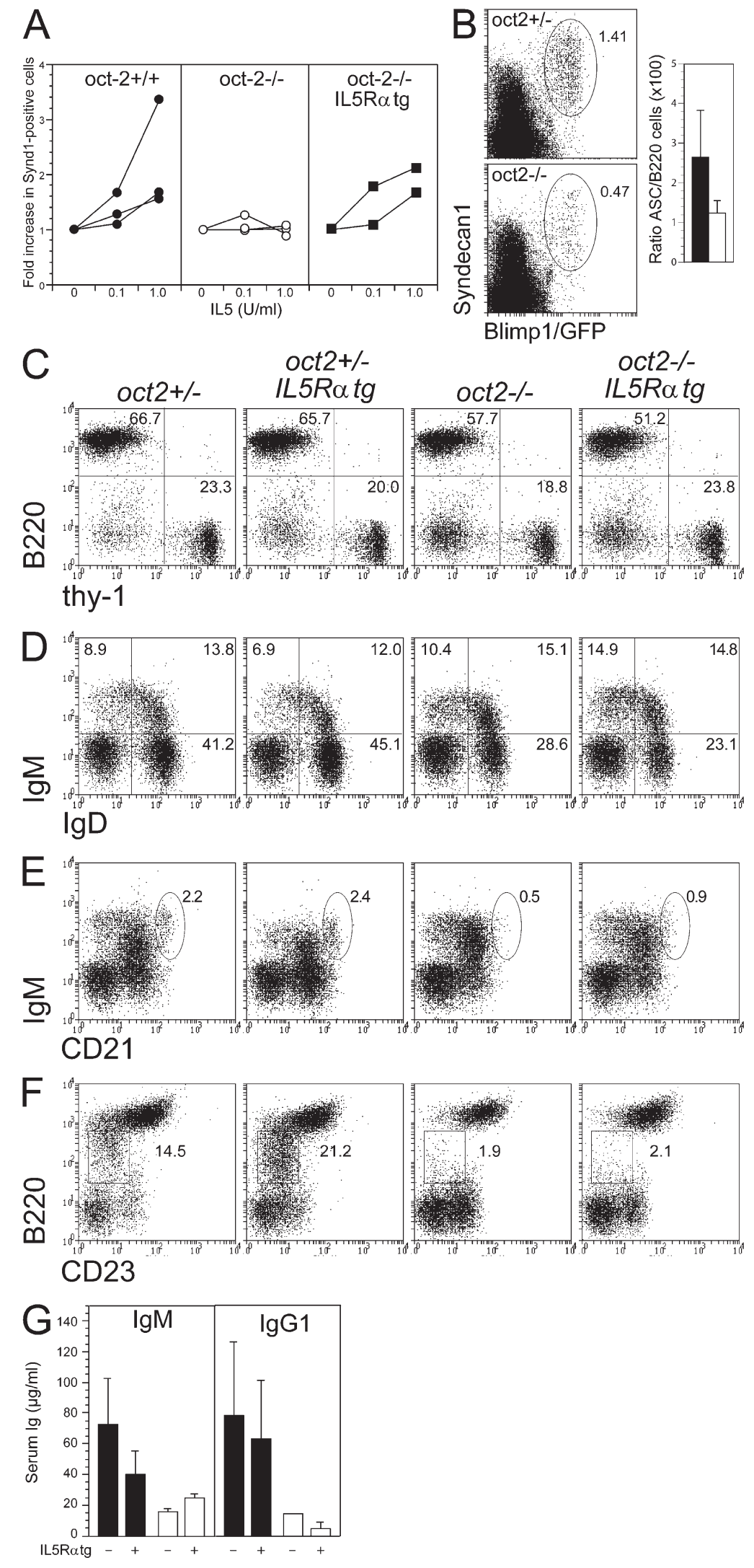

Figure 5. Selective rescue of ASC differentiation by an IL-5R $\boldsymbol{\alpha}$ transgene. (A) Increase in Syndecan $1^{+}$cells generated from resting B cells in culture as a function of increasing IL-5 concentration (CD40L/IL-4 cultures were assessed at day 4). Each line shows the response of cells from an 


\section{IL-5 enhances blimp1/prdm 1 expression}

We next examined the molecular consequences of IL- 5 treatment on B cells. In these assays, the B cells were from a mouse expressing the GFP from the endogenous blimp1 promoter. Thus, all ASCs generated in vivo or in vitro express GFP (30). Addition of IL-5 to CD40L+IL-4 cultures increased the number of cells expressing blimp1/GFP, and the $\mathrm{GFP}^{+}$cells were Syndecan $1^{+}$ASCs (Fig. 2 E and not depicted).

To assess the ability of IL-5 to directly activate transcription of the blimp1 gene, we prepared replicate cultures of WT $\mathrm{B}$ cells in LPS. $3 \mathrm{~d}$ later, cycloheximide (CHX) was added to both cultures at a concentration $(50 \mu \mathrm{M})$ that we determined would inhibit protein synthesis while preserving cell viability. $1 \mathrm{~h}$ later, IL-5 was added to one culture only, and cells were harvested $5 \mathrm{~h}$ after cytokine addition. Quantitative PCR analysis showed that LPS alone is a strong inducer of blimp1 expression, as expected (Fig. 2 F). Addition of CHX did not influence blimp1 messenger RNA levels, but the further addition of IL-5 enhanced blimp1 expression approximately fourfold over LPS alone (Fig. 2 F). Blimp1 up-regulation was observed only in the IL $-5^{+} \mathrm{CHX}$-treated and not the IL- $5^{+}$ DMSO-treated sample. Similar results were obtained in TD culture conditions, using anti-CD40+IL-4 to drive differentiation (Fig. 2 F). These results suggest that the blimp1 gene is repressed by a labile repressor but that release from repression is alone insufficient to activate the gene. The addition of IL-5 rapidly up-regulates blimp1 transcription in the absence of new protein synthesis, most likely through activation and nuclear transport of its cognate signal transducer, Stat5 (31). There are two perfect consensus Stat5 binding sites in the blimp 1 promoter, at positions -1325 and -931 relative to the start of transcription (32).

\section{Oct2 regulates the IL-5R $\alpha$ gene expression in B lymphocytes but not eosinophils}

In addition to its effects on differentiation, IL-5 acts as a coactivator for $\mathrm{B}$ cell proliferation when in combination with anti-CD38 (33). This response is also absent in oct $2^{-/-}$ B cells (Fig. 3 A). However, the proliferation of eosinophils, another IL-5-responsive cell type, was not dependent on Oct2. Oct $2^{-/-}$fetal liver stem cells cultured in IL-5 gave rise to normal numbers of eosinophil colonies of normal size (Fig. 3 B). Therefore, expression of the IL-5R is regulated differently in B cells and eosinophils.
As B cells required Oct 2 to respond to IL- 5 in all assays that we have performed, we assessed whether the IL-5R might require Oct2 for its expression. Although the IL-5R $\beta$ chain was not affected in the mutants (not depicted), quantitative PCR analysis showed that the IL-5R $\alpha$ chain was expressed at abnormally low levels in primary B cells from oct $2^{-1-}$ mice compared with control B cells (Fig. 3 C). Indeed, the loss of Oct2 had an even more dramatic effect on expression of this new putative target gene than was seen for the bona fide Oct2 target, CD36 (Fig. 3 C) $(34,35)$.

To begin to dissect the mechanism of action of Oct2 on the IL-5R $\alpha$ gene, we made use of OM1 A, a cloned oct $2^{-/-}$ $\mathrm{B}$ lymphoma cell line, and a cloned derivative that had been transduced with a retroviral construct expressing an Oct2estrogen receptor (ER) fusion protein (36). In the absence of estradiol, Oct2-ER is cytoplasmic, and induction causes the Oct2-ER protein to moved quickly and quantitatively to the nucleus (unpublished data). The cells were induced with estradiol in the presence of CHX to ask whether Oct 2 could directly activate transcription of the endogenous IL-5R $\alpha$ gene. Interestingly, in contrast to the $\mathrm{CD} 36$ gene, estradiol ${ }^{+} \mathrm{CHX}$ modestly increased IL-5R $\alpha$ expression in the absence of Oct2-ER, implying that IL-5R $\alpha$ is normally repressed by a labile factor. Induction of Oct2 dramatically enhanced both CD36 and IL-5R $\alpha$ transcription in the absence of new protein synthesis (Fig. $3 \mathrm{D}$ ), suggesting that Oct2 acts directly to activate the IL-5R $\alpha$ gene.

\section{Oct2 binds to the IL-5R $\alpha$ gene promoter}

Using 5' rapid amplification of complementary DNA (cDNA) ends (RACE), we found that the majority of IL-5R $\alpha$ transcripts in the spleen were initiated at or very near the A residue at position $-4870 \mathrm{bp}$ from the start of translation (or $166 \mathrm{bp}$ upstream of the $5^{\prime}$ end of the IL-5R $\alpha$ reference cDNA sequence, available from GenBank/EMBL/DDBJ under accession no. NM_008370; Fig. 4 A). The adjacent sequences did not contain a classical TATA box, but a 5-bp AT-rich sequence was found at approximately position -30 from the putative start of transcription. In their review of the features of eukaryotic promoters, Smale and Kadonaga (37) note that AT-rich sequences at approximately position -30 can profoundly influence promoter strength, even if they do not resemble the TATA consensus. In addition, there is a five out of seven match to the consensus initiator sequence (37) near the common $5^{\prime}$ end of

independent reconstituted mouse of the indicated genotype. The percentages of Syndecan $1^{+}$cells were made relative to the percentage generated without IL-5 for each sample, and the IL-5-dependent fold increase is displayed. This was done to enable comparison between experiments, as the mice in each cohort varied somewhat in their levels of B cell reconstitution, and the staining and analysis gates used on different days also varied slightly. The percentages of Syndecan $1^{+}$cells in the non-IL-5 cultures ranged from 3 to $7.6 \%$ across the eight animals assessed. (B, left) Dot plot showing Syndecan $1^{+}$ $\left(\mathrm{GFP}^{+}\right) \mathrm{ASC}$ (circled) in the spleens of mice reconstituted with oct $2^{+1-}$ or oct $2^{-1-}$ B cells expressing the blimp $1 / \mathrm{gfp}$ reporter allele. (right) Means of analyses of three animals (+SD) of each genotype (shaded bar, oct2 ${ }^{+1-}$; open bar, oct2 ${ }^{-1-}$ ). (C-G) Flow cytometric analysis of tissues of Rag $1^{-1-}$ mice reconstituted with the fetal liver from embryonic day 13 mice of the indicated genotypes (percentages are shown). (C) Splenocytes stained for B cell (B220) and T cell (thy-1) markers. (D) Splenic B cells stained with anti-IgM and anti-IgD as markers of maturity. (E) Spleens stained to identify MZ B cells $\left(\mathrm{IgM}^{\mathrm{hi}}\right.$ and $\mathrm{CD} 21^{\text {hi }}$; circled). (F) Peritoneal lavage cells stained to detect the B-1 population (boxed). Equivalent results were obtained using B220 and Mac1/CD11b to identify B-1 cells (not depicted). (G) Serum Ig levels in naive mice (mean \pm SD for four mice of each genotype; shaded bars, oct2 ${ }^{+/+}$; open bars, oct $2^{-1-}$ ). 
the IL-5R $\alpha$ RACE products. These features suggest that the preferred transcriptional start site for the IL-5R $\alpha$ gene in splenocytes (of which B lymphocytes are the major cell type) lies in this region.

A search of the upstream sequence of the IL-5R $\alpha$ gene using the ConSite transcription factor binding site search tool (38) revealed two nonconsensus octamer motifs (Fig. 4 A). Two methods were used to determine whether Oct2 is able to bind directly to these sites. First, chromatin immunoprecipitation (ChIP) was performed, using chromatin isolated from control WEHI231 or Oct2-deficient OM1A B lymphoma cell lines and a polyclonal anti-Oct 2 antiserum. The results indicated that Oct 2 bound specifically to chromatin in the IL-5R $\alpha$ promoter in the vicinity of the two octamer motifs (5' ChIP) and to the CD36 promoter, a known Oct2 target gene (Fig. 4 B). Two independent experiments are shown, and the relative enrichments (using WEHI $231^{+}$preimmune serum as the reference sample) differ between experiments because the second experiment had a lower level of nonspecific immunoprecipitation overall. EMSA was used to learn whether one or both of the octamer motifs were bound by Oct 2 . IL-5R $\alpha$ octamer site 1 (the most $5^{\prime}$ ) was able to bind to a nuclear protein, forming a complex that had the same mobility as an Oct2-consensus octamer DNA complex $\left(\mathrm{V}_{\mathrm{H}}\right.$ octa) and that was specifically supershifted by a monoclonal anti-Oct2 antibody (Fig. 4 C). The more 3' IL-5R $\alpha$ octamer site 2 did not exhibit specific binding to Oct2. Collectively, these data indicate that Oct2 binds directly to the promoter of the IL-5R $\alpha$ gene to activate its transcription specifically in B cells.

\section{Provision of an IL-5R $\alpha$ transgene selectively rescues ASC differentiation in oct $2^{-l-} B$ cells}

We crossed the oct 2 mutant mice to a transgenic mouse strain expressing the IL-5R $\alpha$ gene constitutively in B cells (39) to determine whether enforced expression of IL-5R $\alpha$ could rescue some aspects of the oct 2 mutant phenotype. Because oct $2^{-/-}$mice do not survive postnatally, all experimental mice were generated using adoptive transfer of fetal liver stem cells into Rag1-/- recipients. The reconstituted mice were analyzed after at least 2 mo of reconstitution. We specifically assessed the ability of the transgene to complement the defective ASC differentiation of oct $2^{-/-}$B cells identified in vitro (Fig. 1). Purified, resting splenic B cells from mice reconstituted with control, oct2-null or oct2-null/ IL-5R $\alpha$ transgenic fetal liver stem cells were cultured in CD40L+IL-4 in the presence or absence of IL-5. After $4 \mathrm{~d}$, cells were harvested and stained for Syndecan 1 expression, and antibody in culture supernatants was measured by ELISA. IL-5 increased the proportion of Syndecan $1^{+}$cells in the control but not the oct 2 -deficient cultures. The IL-5R $\alpha$ transgene largely restored the ability of oct $2^{-/-}$cells to differentiate in response to IL-5 in a concentration-dependent manner, generating a higher percentage of Syndecan $1^{+}$cells and a corresponding increase in secreted $\mathrm{Ig}$ in the cultures (Fig. $5 \mathrm{~A}$ and not depicted). These reconstitution studies indicate that a primary role of Oct 2 in these TD cultures is to activate the IL-5R $\alpha$ gene, enabling efficient differentiation of ASCs. We also observed a lower proportion of Syndecan $1^{+}$ASCs in the spleens and bone marrow of mice reconstituted with oct $2^{-/-}$B cells expressing the blimp1/gfp reporter allele compared with controls (Fig. 5 B and not depicted). This may reflect, in part, a deficiency of ASCs that would have been generated in vivo during TD responses to environmental antigens, mediated by IL- 5 through Oct 2 and IL- $5 \mathrm{R} \alpha$.

We found that the IL-5R $\alpha$ transgene did not convincingly rescue any of the other defects of the $\mathrm{B}$ cell lineage of oct 2 mutant mice in vivo. For example, the proportion of $\mathrm{B}$ cells in the spleen remained low (Fig. 5 B), and there was an abnormally high percentage of immature cells in the spleen of oct2-null mice, whether or not they bore the IL-5R $\alpha$ transgene (Fig. 5 C). Similarly, the transgene failed to rescue the marginal zone (MZ) or B-1 cell populations of the oct $2^{-/-}$ mice (Fig. 5, D and E). It was regularly noted that the B-1 compartment of control transgenic mice was larger than control nontransgenics, consistent with the reported activity of the transgene and the particular responsiveness of B-1 cells to IL-5 (6). The failure of the transgene to complement these defects highlights the selective role that IL-5 and its receptor play during B cell development, and emphasizes the fact that Oct2 regulates other genes important for normal B lymphocyte development and function, such as those mediating BCR signaling (23).

\section{DISCUSSION}

Recently, many groups have worked to elucidate the intrinsic factors that are required for the differentiation of antigenactivated B cells into ASCs (7). These studies have identified essential transcriptional regulators, such as Blimp1, Bach2, Bcl6, IRF4, Xbp-1, and Pax5, whose activities orchestrate the transition from the mature B cell and germinal center genetic programs to one dedicated to high level Ig synthesis and secretion. Less clear are the modes of action of extrinsic signals, as well as their associated downstream signaling pathways, in initiating or enhancing this important transition. In this study, we consider the T cell-derived cytokine IL-5 as one such extrinsic signal.

In the mouse B cell lineage, IL-5 seems to serve primarily as an enhancer of antibody. It supports cells of the B-1 cell lineage, which constitutively express IL-5R $\alpha(27,40)$. These cells are the source of most "natural" Ig in the serum and are poised to differentiate very rapidly to ASCs upon activation (41). Resting follicular B cells are unresponsive to IL-5. We show that two T cell signals, CD40L and IL-4, strongly synergize to condition splenic B cells to become IL-5 sensitive. This dramatic synergy would ensure that only those B cells activated in the context of T cell help could be accelerated toward ASC differentiation by IL-5. In follicular B cells, IL-5 has a clear and specific activity in enhancing ASC differentiation from follicular B cells (Fig. 1) (1). Finally, IL-5 has been shown to improve the survival of BMderived plasma cells (42). We show that Oct2 is required for 
B cells to be able to effectively "read" this T cell signal. Oct 2 binds directly to the promoter of the IL-5R $\alpha$ gene and increases its transcription in splenic B cells. We have demonstrated a dependence on Oct 2 during ASC differentiation in vitro in response to IL-5 stimulation, as well as a specific improvement of differentiation efficiency when IL-5R $\alpha$ was provided to Oct2-deficent B cells as a transgene.

Overexpression of IL-5 has been shown to significantly increase antibody levels in vivo, predominantly from an expanded population of B-1 cells (40). Conversely, IL-5R $\alpha$-deficient or IL-5-depleted mice showed impaired B-1 cell development and reduced serum $\operatorname{IgM}, \operatorname{IgG} 3$ and mucosal $\operatorname{IgA}(6,39,43)$. The IL-5R $\alpha$ transgene used in this study supported increased percentages of peritoneal B-1 cells in control mice but no rescue of this population in the oct $2^{-/-}$mutants (Fig. 5 E). Furthermore, it was not possible to rescue the serum antibody defect in oct2-deficient animals by reconstitution with this single Oct 2 target gene (Fig. 5 F), probably because serum Ig mainly comprises IgM from B-1 cells, and TD ASCs represent a minority of both cells and Ig in vivo. The contribution of other Oct2 target genes to antibody responses, through BCR signaling, B-1 and MZ B cell populations, and TLR 4 signaling (important for both TI and TD humoral responses) (44), probably overshadows the effect of IL-5 in vivo.
It is not yet known whether Oct 2 contributes to human TD ASCs through IL-5, or another cytokine, in an analogous way to the mouse. There is less evidence for a role of IL-5 on human B lymphocytes, although actions of IL-5 on human $\mathrm{B}$ cells have been reported $(45,46)$. Instead, IL-6 and/or IL-10 induce ASC differentiation of CD40L-activated human B cells in vitro (47-49). Both IL-6 and IL-10 signal through Stat3, as can IL-5 (50).

Our in vitro evidence (Fig. $2 \mathrm{E}$ and not depicted) suggesting that IL-5 alone is unable to up-regulate blimp1 expression in mouse B cells indicates that the blimp1 gene is insulated against untimely induction. Here, a short pulse of IL-5 was only able to stimulate blimp1 expression after $3 \mathrm{~d}$ of culture. At earlier time points (24-48 h of culture), blimp1 expression was not influenced by IL-5 addition (unpublished data). These observations accord with those reported by Horikawa et al. (2) showing that IL-5 induces blimp1 in CD38-activated B cells slowly (over several days). These observations, the requirement for several cell divisions before ASC differentiation occurs in vitro (1), and the positive effect that an inhibitor of protein synthesis had on blimp1 expression (Fig. 2) are all consistent with the obligate loss of a blimp1 repressor over the first hours and days of activation. Once the repression is released, the blimp1 gene of a plasma cell precursor

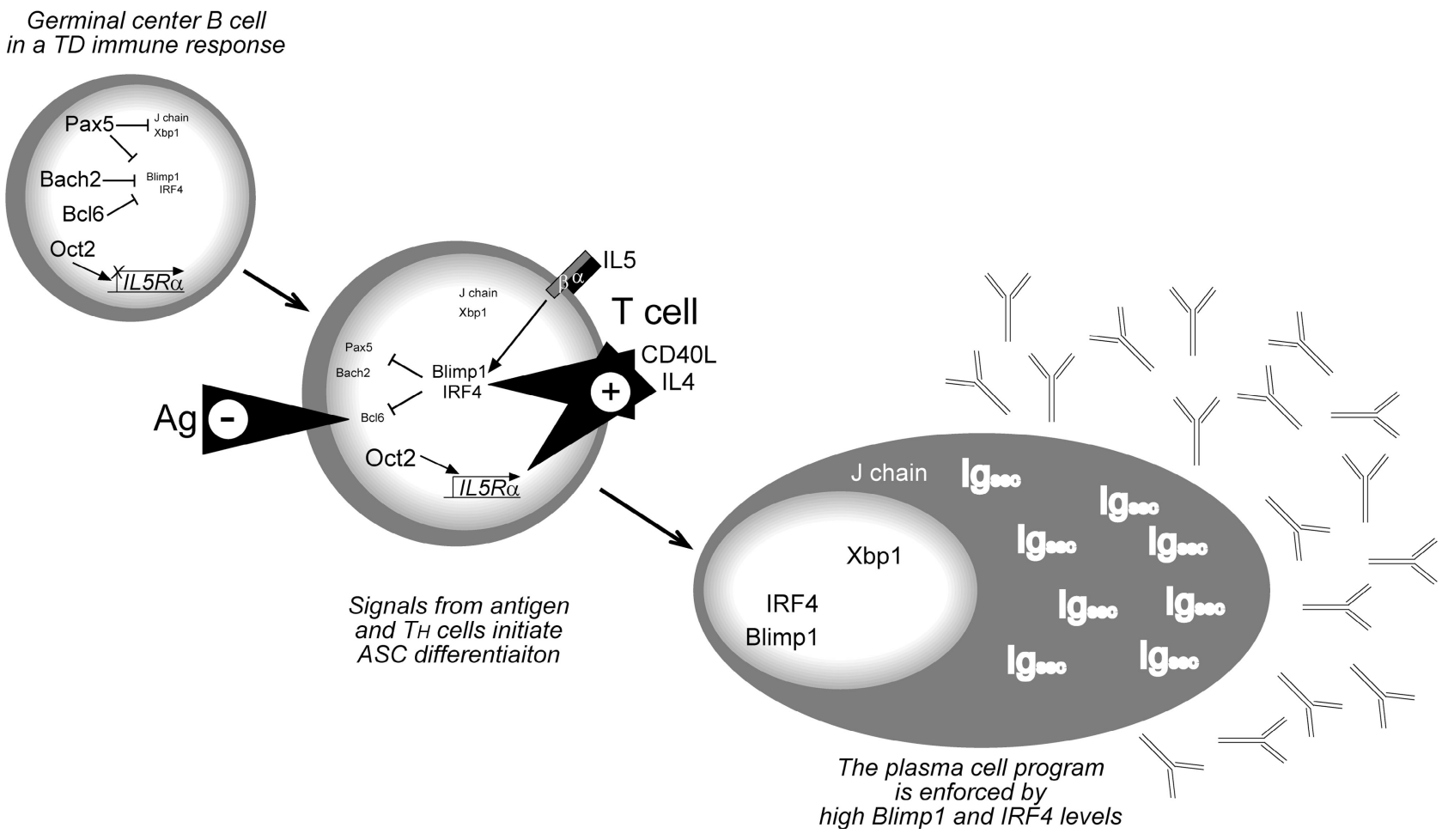

Figure 6. A model for the specific impact of extrinsic signals on the intrinsic regulation of TD ASC differentiation. The phenotype and behavior of germinal center $B$ cells is maintained through the repressive activities of $B c \mid 6, B a c h 2$, and Pax5. Upon immune activation, antigen can signal Bcl6 degradation, and T cells, through CD40, can magnify this effect by activating IRF4, a repressor of Bcl6 transcription (reference 59). T cell-derived cytokines, such as IL-4 and IL-5 (see Results), combine to activate blimp1 transcription. Pax5 protein activity is down-modulated by an unknown mechanism (reference 17). Once Blimp1 and IRF4 reach sufficiently high levels (and Bcl6, Pax5, and Bach2 levels have been reduced), the ASC program is reinforced by unopposed repression of Bcl6, Pax5, and Bach2 by the plasma cell determinants IRF4 and Blimp1. 
would become responsive to the positive influence of IL-5 signaling. Strong candidates for the blimp1 repressors are Bc16 (8) and Bach2, which have been shown to bind directly to the blimp1 gene $(51,67)$, and Pax5 $(9,52,53)$. Indeed, Horikawa et al. showed that bcl6 messenger RNA levels declined within hours of IL-5 addition in their culture system (2), and Kallies et al. showed that a reduction of Pax5 activity precedes blimp1 induction (17).

In vivo, signals that derepress the blimp 1 gene are likely to come from $\mathrm{T}$ cells and their products and through the BCR, as has been proposed by Niu et al. (18). In one model, Bcl6 competes for binding on the blimp1 gene with the transcriptional activator Stat3, with which it shares a consensus DNA binding motif (54). A strong BCR signal leads to degradation of Bcl6, vacating the DNA binding site in favor of Stat3, which is activated in response to IL-6 and other cytokines. It is intriguing to note that Stat3 binds to the same consensus DNA binding motif as Stat5 (55). Stat5 is a major transducer of signals from the IL-5R (56). Thus, Bcl6 and Stat5 may also compete as negative and positive regulators of blimp1 expression.

Recent work has highlighted the importance of the combined influences of blimp1 and IRF4 during ASC differentiation $(17,57,58)$. Thus a model for TD ASC differentiation in vivo (Fig. 6) may incorporate the combined effects of antigen receptor signaling (to relieve $\mathrm{Bcl} 6$ repression) and T cell signals: a CD40 signal to up-regulate IRF4 expression through the canonical NF- $\mathrm{KB}$ pathway and to further reduce Bcl6 expression (59), and cytokines such as IL-5, which boost the expression of the blimp1 gene (Fig. 2 F). Once blimp1 and IRF4 levels reach a critical threshold, a mutual reinforcement has been proposed $(57,58)$ that drives the ASC differentiation program forward.

Both Oct2 and OBF1 have been shown by genetic models to be entirely dispensable for Ig gene expression in B cells and plasma cells. However, these two transcription factors are required for some of the main "sensing" functions of B cells (e.g., Oct2 for LPS sensing through TLR4, and Oct2 and OBF1 for antigen signaling through the BCR and for cytokine responses; see Results; unpublished data). As a result, many aspects of peripheral $\mathrm{B}$ cell behavior are faulty in the mice. $\mathrm{OBF} 1^{-/-}$mice lack germinal centers and $\mathrm{MZ} \mathrm{B}$ cells, and display a reduced mature $\mathrm{B}$ cell pool $(60,61)$. Oct2-null mice also lack MZ B cells and most mature B cells, as well as the B-1 cell population (unpublished data) (24). In the face of these many defects, it was difficult to discern their specific roles in ASC differentiation. Using quantitative in vitro analyses, novel modes of action for Oct2 and OBF1 have been discovered, whereby each is required for a different aspect of TD terminal ASC differentiation (see Results) (19). The influence of each factor on serum Ig is indirect and molecularly distinct, with OBF1 required for TD but not TI ASC differentiation, and with Oct2 enabling the IL-5 response. The latter defect was molecularly characterized and specifically corrected in the studies described in this paper. Such approaches strongly complement global gene expression studies to determine the physiological roles of tissue-restricted gene regulators such as Oct2 and OBF1.

\section{MATERIALS AND METHODS}

Cell preparation and culture. All mice used in the study were on a C57BL/6 genetic background, including the blimp1-GFP reporter (30) and IL-5R $\alpha$ transgenic mice (39). All animal studies were approved by the Animal Ethics Committee of the Royal Melbourne Hospital Research Foundation. Splenic B cells were prepared as previously described (19), using antiCD45R/B220-coupled magnetic beads (Miltenyi Biotec). For CFSE labeling experiments, Percoll gradients were included to enrich for resting cells, as previously described (1). Soluble CD40L and recombinant IL-4 and IL-5, purified from baculovirus-infected Sf9 cells (both used at 1,000 U/ml unless otherwise noted in the figures), and LPS (from $10 \mu \mathrm{g} / \mathrm{ml}$ Escherichia coli 0111: B4; Sigma-Aldrich) were used as previously described (1, 19). Anti-CD38 (NIM-R5) and anti-CD40 (FGK-4.5) were purified from hybridomas provided by M. Howard (ChemoCentryx Inc., Mountain View, CA) and A. Rolink (University of Basel, Basel, Switzerland), and were used at $10 \mu \mathrm{g} / \mathrm{ml}$. $\left[{ }^{3} \mathrm{H}\right]$ Thymidine incorporation was used as previously described (23) to measure proliferation in vitro.

Embryonic day 18 fetal liver cells were cultured at 25,000 cells per milliliter in 1-ml cultures of Dulbecco's modified Eagle's medium with $20 \%$ fetal calf serum and $0.3 \%$ agar. The reagents used to stimulate eosinophil colony formation were $0.1 \mathrm{ml}$ of pokeweed mitogen-stimulated spleen-conditioned medium containing GM-CSF and IL-3, or $10 \mathrm{ng} / \mathrm{ml} \mathrm{IL-5,} \mathrm{as} \mathrm{a} \mathrm{specific} \mathrm{stimulus} \mathrm{for}$ eosinophil colony formation. Cultures were scored after $7 \mathrm{~d}$. Cell counts \pm SD were made on individual colonies in the stained cultures.

For the experiments in Fig. 2 F, the sensitivity of LPS-activated B cells to CHX was determined. B cells were cultured in LPS for $3 \mathrm{~d}$, and then for $6 \mathrm{~h}$ with increasing concentrations of $\mathrm{CHX}$, after which viability (using propidium iodide exclusion) and protein translational activity (using incorporation of $1 \mu \mathrm{Ci}$ per well of $\left[{ }^{35} \mathrm{~S}\right]$-Express protein labeling mix; Perkin Elmer) were measured. At $50 \mu \mathrm{M}$ CHX, translation was completely inhibited, but cell viability was equivalent to control cultures treated with DMSO only (not depicted). B cells were cultured for $3 \mathrm{~d}$ with the stimuli shown in Fig. 2 F, CHX or DMSO were added, and IL-5 was added to selected cultures $1 \mathrm{~h}$ later. Cells were harvested for RNA from all cultures $5 \mathrm{~h}$ after cytokine addition.

The oct $2^{-/-}$B lymphoma cell line OM1A (36) was infected with a retroviral vector (pMX-pie) (62) expressing GFP and oct2 fused to the hormone binding domain of the human ER from a single transcript. Puromycin resistant clones were selected for high GFP expression, and the $\beta$-estradiol-inducible nuclear translocation of the oct2-ER fusion protein was confirmed by subcellular fractionation and Western blotting (unpublished data). For the induction experiments in Fig. $3 \mathrm{D}$, a clone of OM1A-oct2-ER was cultured with $50 \mu \mathrm{M}$ $\mathrm{CHX}$ (or DMSO as a vehicle control). $1 \mathrm{~h}$ later, IL-5 was added to the indicated cultures, and the cells were harvested for RNA after a further $5 \mathrm{~h}$.

Flow cytometry. Anti-Syndecan1 (281-2), anti-CD125 (T21), and antiB220 (RA3-6B2; all PE conjugated), and anti-thy-1.2 (30-H12), anti-IgM (R6-60.2), anti-IgD (11-26c.2a), and anti-CD23 (B3B4; all FITC conjugated) were purchased from BD Biosciences. Anti-CD21 was purified from a hybridoma supplied by K. Inoue (Osaka University Medical School, Osaka, Japan) and biotinylated. A. Strasser (Walter and Eliza Hall Institute, Melbourne, Australia) purified the NimR-5 (anti-CD38) antibody. CFSE labeling was performed as previously described (1).

ELISPOT and ELISA. In Fig. 1 B, 200 sorted Syndecan $1^{+}$cells from day 4 of a culture (CD40L + IL-4) of resting B cells were plated for ELISPOT assay, performed essentially as previously described (1) using anti-Igא-coupled horseradish peroxidase as the developing reagent. For the ELISA assay, 6,000 sorted Syndecan $1^{+}$cells were plated in medium without stimuli, and the culture supernatants were harvested 6 h later. Measurement of Igא, IgM, and IgG1 levels in culture supernatants, or Ig levels in serum, was performed as previously described (63). 
Quantitative RT-PCR. First-strand cDNA was transcribed (SuperScript III First-Strand Synthesis System; Invitrogen) from total RNA (RNeasy Mini Kit; QIAGEN) using the manufacturers' protocols. Real-time PCR analysis was performed using an SYBR green system (Quantitect; QIAGEN), according to the manufacturer's instructions. The expression data were analyzed on a sequence detection system (ABI Prism 7900HT; Applied Biosystems), using relative quantification of gene expression. Expression was normalized using hydroxymethylbilane synthase (Hmbs) as a housekeeping gene. For the ChIP assays, the absolute quantification using standard curves was used to measure the products for PCR reactions.

Primers used for cDNA amplification were as follows: Hmbs, (forward) 5'-GACCTGGTTGTTCACTCCCTGAAG-3' and (reverse) 5'-GACAACAGCATCACAAGGGTTTTC-3'; CD36, (forward) 5'-CAGCTCATACATTGCTGTTTATGCATG-3' and (reverse) 5'-GGTACAATCACAGTGTTTTCTACGTGG-3'; oct2, (forward) 5'-GCATCGAGACGAATGTCCGCTTCG-3' and (reverse) 5'-GTAGCTGGTCGGCTTTCCCGGGCT-3'; IL-5R $\alpha$, (forward) $5^{\prime}$-CAGTGGGAGAAACCACTTTCTGCC-3' and (reverse) 5'-GAGATGCCATTCTACCAAGGACTTC-3'; and blimp1, the QuantiTect Primer Assay for Mm_Prdm1 (QIAGEN).

5' RACE. The transcriptional start site for the mouse IL-5R $\alpha$ gene was mapped using a RACE cDNA amplification kit (SMART; BD Biosciences). Gene-specific nested primers were $5^{\prime}$ IL-5R $\alpha-1$ (5'-GCGTTAGCTCTGTCTCTGCTGATAACAGGGC- $\left.3^{\prime}\right)$ and $5^{\prime}$ IL-5R $\alpha-2$ (5'-CTGCATACCGGGACCTGTCCAGTGAGCTTC- $3^{\prime}$ ). A single prominent product was generated from the $5^{\prime}$ RACE PCR reaction, which was purified from an agarose gel, and cloned. At least one dozen clones were bidirectionally sequenced to ensure that microheterogeneities in sequence length were not overlooked.

ChIP. ChIP was performed essentially as described by Ramirez-Carrozzi et al. (64). Specifically, chromatin from $1.2 \times 10^{8}$ WEHI231 and OM1A cells was cross-linked using $1 \%$ formaldehyde for $10 \mathrm{~min}$ at room temperature. The cells were collected after two cold PBS washes, resuspended in 10 $\mathrm{ml}$ of cell lysis buffer ( $5 \mathrm{mM}$ Pipes [pH 7], $85 \mathrm{mM} \mathrm{KCl}, 0.5 \% \mathrm{NP}-40)$, and lysed for $10 \mathrm{~min}$ on ice. Nuclei were resuspended in $1 \mathrm{ml}$ of nuclei lysis buffer (50 mM Tris-HCl [pH 7], $10 \mathrm{mM}$ EDTA, 1\% SDS) and sonicated with 30-s pulses using a sonifier (Branson) until the DNA was reduced in size to $\sim 500 \mathrm{bp}$. The purified chromatin $(350 \mu \mathrm{g})$ was diluted twofold with ChIP dilution buffer (16.7 mM Tris-HCl [pH 7], $167 \mathrm{mM} \mathrm{NaCl}, 1.2 \mathrm{mM}$ EDTA, $0.01 \%$ SDS, $1.1 \%$ Triton X-100) supplemented with $100 \mu \mathrm{g} / \mathrm{ml}$ of sonicated herring sperm DNA and protease inhibitors. After preclearing with $100 \mu \mathrm{l}$ of protein $\mathrm{G}$-sepharose for $2 \mathrm{~h}$ at $4^{\circ} \mathrm{C}$, the diluted chromatin was immunoprecipitated overnight at $4^{\circ} \mathrm{C}$ using $5 \mu$ l of rabbit anti-Oct 2 antiserum (26) or preimmune serum. Immune complexes were recovered by a $2-\mathrm{h}$ incubation at $4^{\circ} \mathrm{C}$ with $50 \mu$ l of protein $\mathrm{G}$-sepharose, washed once each with low-salt buffer (50 mM Hepes [pH 7], $0.15 \mathrm{M} \mathrm{NaCl}, 1 \mathrm{mM}$ EDTA, 0.1\% SDS, 1\% Triton $\mathrm{X}-100,0.1 \%$ deoxycholate), high-salt buffer (the same as low-salt buffer but with $0.5 \mathrm{M} \mathrm{NaCl})$, and $\mathrm{LiCl}$ wash buffer $(0.25 \mathrm{M} \mathrm{LiCl}, 1 \% \mathrm{NP}-40,1 \%$ sodium deoxycholate, $1 \mathrm{mM}$ EDTA, $10 \mathrm{mM}$ Tris- $\mathrm{HCl}$ [pH 7]), and twice with TE (10 mM Tris-HCl [pH 8], 1 mM EDTA). The DNA was extracted with $500 \mu \mathrm{l}$ of elution buffer $\left(0.1 \mathrm{M} \mathrm{NaHCO}_{3}, 1 \% \mathrm{SDS}\right)$, supplemented with $0.2 \mathrm{M} \mathrm{NaCl}$, and incubated overnight at $65^{\circ} \mathrm{C}$ to reverse DNA crosslinks. $10 \mathrm{mM}$ EDTA, $40 \mathrm{mM}$ Tris- $\mathrm{HCl}(\mathrm{pH} 7)$, and $80 \mu \mathrm{g} / \mathrm{ml}$ proteinase $\mathrm{K}$ were added, and after a further $4-5 \mathrm{~h}$ at $45^{\circ} \mathrm{C}$, the DNA was extracted with phenol/chloroform and precipitated. PCR to detect immunoprecipitated DNA used the following primers: CD36 ChIP, (forward) 5'-CCTTGTGAGCTTAACTAGCAGTGAAGTGTG-3' and (reverse) 5'-CCAGTTGCTCCACACATTTCAGAAGGCAGC- $3^{\prime}$; IL-5R $\alpha 5^{\prime}$ ChIP, (forward) 5'-GACGGATGAGCTGGGTCAGGCTAGATAG-3' and (reverse) 5' CAATCTGAGAACTCTGCGAGCTTTAGCC-3'; and IL-5R $\alpha 3^{\prime}$ ChIP, (forward) 5'-GGCTAAAGCTCGCAGAGTTCTCAGATTG-3' and (reverse) 5'-GCGTTAGCTCTGTCTCTGCTGATAACAGGGC-3'.

EMSA. Nuclear extracts were prepared (65) and EMSA was performed (26) as previously described. Probes were annealed, and double-stranded oligonucleotides were labeled using $\left[{ }^{32} \mathrm{P}\right] \mathrm{dATP}$ and Klenow DNA polymerase. Oligo sequences were as follows: IL-5R $\alpha$ octa-1, (forward) $5^{\prime}$-GGGGTCACATATCAGATATCTTGCATATCAGATATC-3' and (reverse) $5^{\prime}$-TTTGATATCTGATATGCAAGATATCTGATATGTGACCCC-3'; IL-5R $\alpha$ octa-2, (forward) 5'-CTCTGCTAGTCACTCAGCATGAAAATCCTCAGACT-3' and (reverse) 5'-TTTAGTCTGAGGATTTTCATGCTGAGTGACTAGCAGAG-3'; and $\mathrm{V}_{\mathrm{H}}$ octa, (forward) $5^{\prime}$-CCTTGCCTCATGAGTATGCAAATCATGTGCGACTG-3' and (reverse) 5'-TTTCAGTCGCACATGATTTGCATACTCATGAGGCAAGG-3'.

Fetal liver reconstitutions. Day 13 embryos were recovered, fetal livers were dissected, and cell suspensions were prepared. After genotyping, the cells of interest were transplanted into irradiated (300 Rad) Rag1 $1^{-/}$recipients, as previously described (23), at a ratio of three recipients per donor liver. Reconstitution was monitored by the appearance of mature lymphocytes in peripheral blood, and only stably reconstituted mice were included in the analyses presented in this paper.

We thank Dr. S. Nutt for critical reading of the manuscript, S. Mifsud and L. DiRago for technical assistance with colony assays, and J. Gilbert and E. Loza for animal care. We also thank Professor T. Speed for guidance on statistical analyses.

This work was supported by the Australian National Health and Research Council and the Cancer Council of Australia, and by a Grant-in-Aid for Scientific Research on Priority Areas from the Japanese Ministry of Education, Culture, Sports, Science and Technology.

The authors have no conflicting financial interests.

\section{Submitted: 21 September 2007}

Accepted: 4 January 2008

\section{REFERENCES}

1. Hasbold, J., L.M. Corcoran, D.M. Tarlinton, S.G. Tangye, and P.D Hodgkin. 2004. Evidence from the generation of immunoglobulin Gsecreting cells that stochastic mechanisms regulate lymphocyte differentiation. Nat. Immunol. 5:55-63.

2. Horikawa, K., and K. Takatsu. 2006. Interleukin-5 regulates genes involved in B-cell terminal maturation. Immunology. 118:497-508.

3. Yoshida, T., K. Ikuta, H. Sugaya, K. Maki, M. Takagi, H. Kanazawa, S. Sunaga, T. Kinashi, K. Yoshimura, J. Miyazaki, et al. 1996. Defective B-1 cell development and impaired immunity against Angiostrongylus cantonensis in IL-5R alpha-deficient mice. Immunity. 4:483-494.

4. Kopf, M., F. Brombacher, P.D. Hodgkin, A.J. Ramsay, E.A. Milbourne, W.J. Dai, K.S. Ovington, C.A. Behm, G. Kohler, I.G. Young, and K.I. Matthaei. 1996. IL-5-deficient mice have a developmental defect in CD5+ B-1 cells and lack eosinophilia but have normal antibody and cytotoxic T cell responses. Immunity. 4:15-24.

5. Itakura, A., Y. Kikuchi, T. Kouro, M. Ikutani, S. Takaki, P.W. Askenase, and K. Takatsu. 2006. Interleukin 5 plays an essential role in elicitation of contact sensitivity through dual effects on eosinophils and B-1 cells. Int. Arch. Allergy Immunol. 140(Suppl. 1):8-16.

6. Moon, B.G., S. Takaki, K. Miyake, and K. Takatsu. 2004. The role of IL-5 for mature B-1 cells in homeostatic proliferation, cell survival, and Ig production. J. Immunol. 172:6020-6029.

7. Calame, K. 2006. Transcription factors that regulate memory in humoral responses. Immunol. Rev. 211:269-279.

8. Shaffer, A.L., X. Yu, Y. He, J. Boldrick, E.P. Chan, and L.M. Staudt. 2000. BCL-6 represses genes that function in lymphocyte differentiation, inflammation, and cell cycle control. Immunity. 13:199-212.

9. Nera, K.P., P. Kohonen, E. Narvi, A. Peippo, L. Mustonen, P. Terho, K. Koskela, J.M. Buerstedde, and O. Lassila. 2006. Loss of Pax5 promotes plasma cell differentiation. Immunity. 24:283-293.

10. Schebesta, A., S. McManus, G. Salvagiotto, A. Delogu, G.A. Busslinger, and M. Busslinger. 2007. Transcription factor Pax5 activates the chromatin of key genes involved in B cell signaling, adhesion, migration, and immune function. Immunity. 27:49-63.

11. Turner, C.A., Jr., D.H. Mack, and M.M. Davis. 1994. Blimp-1, a novel zinc finger-containing protein that can drive the maturation of $\mathrm{B}$ lymphocytes into immunoglobulin-secreting cells. Cell. 77:297-306. 
12. Shaffer, A.L., K.I. Lin, T.C. Kuo, X. Yu, E.M. Hurt, A. Rosenwald, J.M. Giltnane, L. Yang, H. Zhao, K. Calame, and L.M. Staudt. 2002. Blimp-1 orchestrates plasma cell differentiation by extinguishing the mature B cell gene expression program. Immunity. 17:51-62.

13. Shapiro-Shelef, M., K.I. Lin, L.J. McHeyzer-Williams, J. Liao, M.G. McHeyzer-Williams, and K. Calame. 2003. Blimp-1 is required for the formation of immunoglobulin secreting plasma cells and pre-plasma memory B cells. Immunity. 19:607-620.

14. Mittrucker, H.W., T. Matsuyama, A. Grossman, T.M. Kundig, J. Potter, A. Shahinian, A. Wakeham, B. Patterson, P.S. Ohashi, and T.W. Mak. 1997. Requirement for the transcription factor LSIRF/IRF4 for mature B and T lymphocyte function. Science. 275:540-543.

15. Reimold, A.M., N.N. Iwakoshi, J. Manis, P. Vallabhajosyula, E. Szomolanyi-Tsuda, E.M. Gravallese, D. Friend, M.J. Grusby, F. Alt, and L.H. Glimcher. 2001. Plasma cell differentiation requires the transcription factor XBP-1. Nature. 412:300-307.

16. Klein, A.B., S.G. Witonsky, S.A. Ahmed, S.D. Holladay, R.M. Gogal Jr., L. Link, and C.M. Reilly. 2006. Impact of different cell isolation techniques on lymphocyte viability and function. J. Immunoassay Immunochem. 27:61-76.

17. Kallies, A., J. Hasbold, K. Fairfax, C. Pridans, D. Emslie, B.S. McKenzie, A.M. Lew, L.M. Corcoran, P.D. Hodgkin, D.M. Tarlinton, and S.L. Nutt. 2007. Initiation of plasma-cell differentiation is independent of the transcription factor Blimp-1. Immunity. 26:555-566.

18. Niu, H., B.H. Ye, and R. Dalla-Favera. 1998. Antigen receptor signaling induces MAP kinase-mediated phosphorylation and degradation of the BCL-6 transcription factor. Genes Dev. 12:1953-1961.

19. Corcoran, L.M., J. Hasbold, W. Dietrich, E. Hawkins, A. Kallies, S.L. Nutt, D.M. Tarlinton, P. Matthias, and P.D. Hodgkin. 2005. Differential requirement for OBF-1 during antibody-secreting cell differentiation. J. Exp. Med. 201:1385-1396.

20. Fornek, J.L., L.T. Tygrett, T.J. Waldschmidt, V. Poli, R.C. Rickert, and G.S. Kansas. 2006. Critical role for Stat3 in T-dependent terminal differentiation of IgG B cells. Blood. 107:1085-1091.

21. Corcoran, L.M., M. Karvelas, G.J. Nossal, Z.S. Ye, T. Jacks, and D. Baltimore. 1993. Oct-2, although not required for early B-cell development, is critical for later B-cell maturation and for postnatal survival. Genes Dev. 7:570-582.

22. Feldhaus, A.L., C.A. Klug, K.L. Arvin, and H. Singh. 1993. Targeted disruption of the Oct-2 locus in a B cell provides genetic evidence for two distinct cell type-specific pathways of octamer element-mediated gene activation. EMBO J. 12:2763-2772.

23. Corcoran, L.M., and M. Karvelas. 1994. Oct-2 is required early in T cell-independent B cell activation for G1 progression and for proliferation. Immunity. 1:635-645.

24. Humbert, P.O., and L.M. Corcoran. 1997. oct-2 gene disruption eliminates the peritoneal B-1 lymphocyte lineage and attenuates B-2 cell maturation and function. J. Immunol. 159:5273-5284.

25. Schubart, K., S. Massa, D. Schubart, L.M. Corcoran, A.G. Rolink, and P. Matthias. 2001. B cell development and immunoglobulin gene transcription in the absence of Oct-2 and OBF-1. Nat. Immunol. 2:69-74.

26. Corcoran, L.M., F. Koentgen, W. Dietrich, M. Veale, and P.O. Humbert. 2004. All known in vivo functions of the Oct-2 transcription factor require the C-terminal protein domain. J. Immunol. 172: 2962-2969.

27. Hitoshi, Y., N. Yamaguchi, S. Mita, E. Sonoda, S. Takaki, A. Tominaga, and K. Takatsu. 1990. Distribution of IL-5 receptor-positive B cells. Expression of IL-5 receptor on Ly-1(CD5)+ B cells. J. Immunol. 144:4218-4225.

28. Allison, K.C., W. Strober, and G.R. Harriman. 1991. Induction of IL-5 receptors on normal B cells by cross-linking surface Ig with anti-Igdextran. J. Immunol. 146:4197-4203.

29. Weber, J.D., P.C. Isakson, and J.M. Purkerson. 1996. IL-5 receptor expression and Ig secretion from murine $\mathrm{B}$ lymphocytes requires coordinated signaling by membrane Ig, IL-4, and IL-5. J. Immunol. 157: 4428-4435.

30. Kallies, A., J. Hasbold, D.M. Tarlinton, W. Dietrich, L.M. Corcoran, P.D. Hodgkin, and S.L. Nutt. 2004. Plasma cell ontogeny defined by quantitative changes in blimp-1 expression. J. Exp. Med. 200:967-977.
31. Horikawa, K., H. Kaku, H. Nakajima, H.W. Davey, L. Hennighausen, I. Iwamoto, T. Yasue, A. Kariyone, and K. Takatsu. 2001. Essential role of Stat 5 for IL-5-dependent IgH switch recombination in mouse B cells. J. Immunol. 167:5018-5026.

32. Tunyaplin, C., M.A. Shapiro, and K.L. Calame. 2000. Characterization of the B lymphocyte-induced maturation protein-1 (Blimp-1) gene, mRNA isoforms and basal promoter. Nucleic Acids Res. 28:4846-4855.

33. Kikuchi, Y., T. Yasue, K. Miyake, M. Kimoto, and K. Takatsu. 1995. CD38 ligation induces tyrosine phosphorylation of Bruton tyrosine kinase and enhanced expression of interleukin 5-receptor alpha chain: synergistic effects with interleukin 5. Proc. Natl. Acad. Sci. USA. 92:11814-11818.

34. Konig, H., P. Pfisterer, L.M. Corcoran, and T. Wirth. 1995. Identification of CD36 as the first gene dependent on the B-cell differentiation factor Oct-2. Genes Dev. 9:1598-1607.

35. Shore, P., W. Dietrich, and L.M. Corcoran. 2002. Oct-2 regulates CD36 gene expression via a consensus octamer, which excludes the co-activator OBF-1. Nucleic Acids Res. 30:1767-1773.

36. Corcoran, L.M., S. Tawfilis, and L.J. Barlow. 1999. Generation of B lymphoma cell lines from knockout mice by transformation in vivo with an Emu-myc transgene. J. Immunol. Methods. 228:131-138.

37. Smale, S.T., and J.T. Kadonaga. 2003. The RNA polymerase II core promoter. Annu. Rev. Biochem. 72:449-479.

38. Sandelin, A., W.W. Wasserman, and B. Lenhard. 2004. ConSite: webbased prediction of regulatory elements using cross-species comparison. Nucleic Acids Res. 32:W249-W252.

39. Moon, B.G., T. Yoshida, M. Shiiba, K. Nakao, M. Katsuki, S. Takaki, and K. Takatsu. 2001. Functional dissection of the cytoplasmic subregions of the interleukin-5 receptor alpha chain in growth and immunoglobulin G1 switch recombination of B cells. Immunology. 102:289-300.

40. Tominaga, A., S. Takaki, N. Koyama, S. Katoh, R. Matsumoto, M. Migita, Y. Hitoshi, Y. Hosoya, S. Yamauchi, Y. Kanai, et al. 1991 Transgenic mice expressing a $\mathrm{B}$ cell growth and differentiation factor gene (interleukin 5) develop eosinophilia and autoantibody production. J. Exp. Med. 173:429-437.

41. Fairfax, K.A., L.M. Corcoran, C. Pridans, N.D. Huntington, A. Kallies, S.L. Nutt, and D.M. Tarlinton. 2007. Different kinetics of blimp-1 induction in B cell subsets revealed by reporter gene. J. Immunol. 178: 4104-4111.

42. Cassese, G., S. Arce, A.E. Hauser, K. Lehnert, B. Moewes, M. Mostarac, G. Muehlinghaus, M. Szyska, A. Radbruch, and R.A. Manz. 2003 Plasma cell survival is mediated by synergistic effects of cytokines and adhesion-dependent signals. J. Immunol. 171:1684-1690.

43. Hiroi, T., M. Yanagita, H. Iijima, K. Iwatani, T. Yoshida, K. Takatsu, and H. Kiyono. 1999. Deficiency of IL-5 receptor alpha-chain selectively influences the development of the common mucosal immune system independent IgA-producing B-1 cell in mucosa-associated tissues. J. Immunol. 162:821-828.

44. Pasare, C., and R. Medzhitov. 2005. Control of B-cell responses by Toll-like receptors. Nature. 438:364-368.

45. Baumann, M.A., and C.C. Paul. 1997. Interleukin-5 and human B lymphocytes. Methods. 11:88-97.

46. Adachi, T., and R. Alam. 1998. The mechanism of IL-5 signal transduction. Am. J. Physiol. 275:C623-C633.

47. Burdin, N., C. Van Kooten, L. Galibert, J.S. Abrams, J. Wijdenes, J. Banchereau, and F. Rousset. 1995. Endogenous IL-6 and IL-10 contribute to the differentiation of CD40-activated human B lymphocytes. J. Immunol. 154:2533-2544.

48. Roldan, E., and J.A. Brieva. 1991. Terminal differentiation of human bone marrow cells capable of spontaneous and high-rate immunoglobulin secretion: role of bone marrow stromal cells and interleukin 6. Eur. J. Immunol. 21:2671-2677.

49. Kawano, M.M., K. Mihara, N. Huang, T. Tsujimoto, and A. Kuramoto. 1995. Differentiation of early plasma cells on bone marrow stromal cells requires interleukin-6 for escaping from apoptosis. Blood. 85:487-494.

50. Murray, P.J. 2007. The JAK-STAT signaling pathway: input and output integration. J. Immunol. 178:2623-2629.

51. Tunyaplin, C., A.L. Shaffer, C.D. Angelin-Duclos, X. Yu, L.M. Staudt, and K.L. Calame. 2004. Direct repression of prdm1 by Bcl-6 inhibits plasmacytic differentiation. J. Immunol. 173:1158-1165. 
52. Usui, T., Y. Wakatsuki, Y. Matsunaga, S. Kaneko, H. Koseki, and T. Kita. 1997. Overexpression of B cell-specific activator protein (BSAP/ Pax-5) in a late B cell is sufficient to suppress differentiation to an Ig high producer cell with plasma cell phenotype. J. Immunol. 158:3197-3204.

53. Delogu, A., A. Schebesta, Q. Sun, K. Aschenbrenner, T. Perlot, and M. Busslinger. 2006. Gene repression by Pax 5 in B cells is essential for blood cell homeostasis and is reversed in plasma cells. Immunity. 24:269-281.

54. Reljic, R., S.D. Wagner, L.J. Peakman, and D.T. Fearon. 2000. Suppression of signal transducer and activator of transcription 3-dependent B lymphocyte terminal differentiation by BCL-6. J. Exp. Med. 192:1841-1848.

55. Decker, T., P. Kovarik, and A. Meinke. 1997. GAS elements: a few nucleotides with a major impact on cytokine-induced gene expression. J. Interferon Cytokine Res. 17:121-134.

56. Takagaki, Y., and J.L. Manley. 1998. Levels of polyadenylation factor CstF-64 control IgM heavy chain mRNA accumulation and other events associated with B cell differentiation. Mol. Cell. 2:761-771.

57. Sciammas, R., A.L. Shaffer, J.H. Schatz, H. Zhao, L.M. Staudt, and H. Singh. 2006. Graded expression of interferon regulatory factor-4 coordinates isotype switching with plasma cell differentiation. Immunity. 25:225-236.

58. Klein, U., S. Casola, G. Cattoretti, Q. Shen, M. Lia, T. Mo, T. Ludwig, K. Rajewsky, and R. Dalla-Favera. 2006. Transcription factor IRF4 controls plasma cell differentiation and class-switch recombination. Nat. Immunol. 7:773-782.

59. Saito, M., J. Gao, K. Basso, Y. Kitagawa, P.M. Smith, G. Bhagat, A. Pernis, L. Pasqualucci, and R. Dalla-Favera. 2007. A signaling pathway mediating downregulation of BCL6 in germinal center B cells is blocked by BCL6 gene alterations in B cell lymphoma. Cancer Cell. 12:280-292.
60. Nielsen, P.J., O. Georgiev, B. Lorenz, and W. Schaffner. 1996. B lymphocytes are impaired in mice lacking the transcriptional co-activator Bob1/OCA-B/OBF1. Eur. J. Immunol. 26:3214-3218.

61. Samardzic, T., D. Marinkovic, P.J. Nielsen, L. Nitschke, and T. Wirth. 2002. BOB.1/OBF.1 deficiency affects marginal-zone B-cell compartment. Mol. Cell. Biol. 22:8320-8331.

62. Krebs, D.L., Y. Yang, M. Dang, J. Haussmann, and M.R. Gold. 1999. Rapid and efficient retrovirus-mediated gene transfer into B cell lines. Methods Cell Sci. 21:57-68.

63. Corcoran, L., D. Vremec, M. Febbraio, T. Baldwin, and E. Handman 2002. Differential regulation of CD36 expression in antigen-presenting cells: Oct-2 dependence in B lymphocytes but not dendritic cells or macrophages. Int. Immunol. 14:1099-1104.

64. Ramirez-Carrozzi, V.R., A.A. Nazarian, C.C. Li, S.L. Gore, R. Sridharan, A.N. Imbalzano, and S.T. Smale. 2006. Selective and antagonistic functions of SWI/SNF and Mi-2beta nucleosome remodeling complexes during an inflammatory response. Genes Dev. 20:282-296.

65. Schreiber, E., P. Matthias, M.M. Muller, and W. Schaffner. 1989 Rapid detection of octamer binding proteins with 'mini-extracts', prepared from a small number of cells. Nucleic Acids Res. 17:6419.

66. Yasue, T., H. Nishizumi, S. Aizawa, T. Yamamoto, K. Miyake, C. Mizoguchi, S. Uehara, Y. Kikuchi, and K. Takatsu. 1997. A critical role of Lyn and Fyn for B cell responses to CD38 ligation and interleukin 5. Proc. Natl. Acad. Sci. USA. 94:10307-10312.

67. Ochiai, K., Y. Katoh, T. Ikura, Y. Hoshikawa, T. Noda, H. Karasuyama, S. Tashiro, A. Muto, and K. Igarashi. 2006. Plasmacytic transcription factor Blimp-1 is repressed by Bach2 in B cells. J. Biol. Chem. 281: 38226-38234. 